\title{
Application of Distance Learning to the Course in Computer Graphics
}

\author{
Biljana Gemović and Nataša Subić \\ Higher Education Technical School of Professional Studies at \\ Novi Sad, Novi Sad, Serbia
}

gemovic@vtsns.edu.rs; subic@vtsns.edu.rs

\begin{abstract}
Distance learning provides the opportunity for a lifelong learning. Learners receive independent professional training at a place and time they choose, they go through the teaching material at their own speed and as many times as they want. Educational materials are the most important element of distance education.

Within the innovative model of work on the course in Computer Graphics, interactive tutorials for every course unit were organized. A tutorial comprises multimedia material which gradually, step by step, presents to a student the way in which graphic objects are created, and thus it teaches a student how to use the tools and functions provided by the program environment of CorelDraw12 and Adobe Indesign CS. Therefore, research was conducted.

The research included 59 students of the study programme Information Technologies $\left(1^{\text {st }}\right.$ year of studying, $2^{\text {nd }}$ semester) at Higher Education Technical School of Professional Studies at Novi Sad. The aim of the research was the efficiency of a contemporary course in Computer Graphics while the subject of research was theoretical and empirical study of students' achievements made by application of innovative models of teaching computer graphics.

The advantages of interactive presentation of teaching material in the distance learning system are enormous. As can be inferred from the data and the diagrams presented in the paper.
\end{abstract}

Keywords: Distance learning, Computer Graphics, interactive tutorials, CorelDraw12, Adobe Indesign CS.

\section{Introduction}

The modern society is characterized by dynamic changes, intensive growth of production, information and telecommunication technologies, which makes way for quality changes in all sectors of society and especially in education. Increase and improvement in the efficiency of education and learning process could be realized through new education models, using a new education

Material published as part of this publication, either on-line or in print, is copyrighted by the Informing Science Institute. Permission to make digital or paper copy of part or all of these works for personal or classroom use is granted without fee provided that the copies are not made or distributed for profit or commercial advantage AND that copies 1) bear this notice in full and 2) give the full citation on the first page. It is permissible to abstract these works so long as credit is given. To copy in all other cases or to republish or to post on a server or to redistribute to lists requires specific permission and payment of a fee. Contact Publisher@InformingScience.org to request redistribution permission. technology. Many foreign educational institutions have tried to deal with this issue by developing a model of distance learning.

Being permanently up-to-date with the latest achievements in the field of educational information and communication technology is a must. The use of information technologies will enable creating of a new basis for improvement of 
teaching process and open new opportunities to it.

\section{Education System in Serbia}

The achievements brought about by the development of a modern society constantly impose the need for changing of education models. Such changes are often very slow due to the volume and inertia of an education system. On the other hand, the process of globalization has led to harmonization of different education models that are also locally specific and thus the education process has surpassed its national context.

Parallel to such changes to the system, there are also individual initiatives attempting to make the education system closer to real needs and possibilities of the environment. One of these initiatives, supported by a strong impulse of a rapid growth of information and communication technology and the advent of the Internet, resulted in modern forms of distance learning. One of the most interesting of these forms is indeed electronic learning (eLearning). At a rapid rate, this initiative has grown into one of the most important strategic points of modern educational institutions, which has led to numerous projects on a national and international level as well.

The education system of our country is undergoing significant changes. Higher schools have been transformed into higher education schools of professional studies and thus got a prominent place in the education system. For students, they represent a ground for acquiring practical knowledge. The organization of a curriculum and syllabus to meet the needs and capabilities of prospective students, the choice of quality teachers and teaching methodologies, all these make contribution to the success of higher education schools of professional studies.

In view of this, the implementation of some of the modern forms of distance learning would indeed be a considerable step forward. In spite of a bad economic situation and lower standard of living, a growing trend in implementation of information and communication technology is perceived in our country. The research conducted in Serbia shows the highest percentage increase of $60 \%$ in the number of the Internet users in the period between 2000 and 2004 and this number is constantly on the rise. The same research shows that $35.5 \%$ of all Internet users are students or pupils, while even $78.5 \%$ of Internet users possess their own PC at home.

The traditional way of education where the teacher is active and learners are mere passive observers of classroom happenings should be combined with modern education which is learnercentred and which puts special emphasis on building up a learner's personality and the way of acquiring knowledge by being active in team or individual work. What also should be pointed out is the importance of the use of information technologies as powerful "tools" in the process of acquiring knowledge. Advantages are enormous because, for example, by using electronic information resources and the Internet one can use many resources that provide information in various ways and forms, such as: text, pictures, sound, video, film etc.

\section{Distance Learning and E-Learning}

The introduction of educational technologies provides new opportunities for interpersonal communication. (Rizvic, Kunovac 1998.) Thus, various distance learning courses and similar projects tend to substitute for a classical form of classroom education. These forms of education, learning without direct contact between the person who conducts the educational process (teacher, tutor) and those being taught (learners, students) are called "Distance Education" or "ELearning". Such education is used in various situations, for example, when learners are not able to attend lectures due to work obligations or geographical distance. 
Distance learning provides the opportunity for a lifelong learning. Learners receive independent professional training at a place and time they choose, they go through the teaching material at their own speed and as many times as they want. (Rizvic, Kunovac 1998.)

Regarding distance learning, there are several terms in use: Distance Learning, Distance Training, Distance Education, eLearning (e-Learning, "e"Learning), Online (On-line) Education, Virtual Instruction, Virtual Education. Taking these terms as synonyms is not a coincidence. What all of them have in common is the fact they assume the learning process in which knowledge resource and a receiver are physically far away and their relationship is mediated through the use of ICT, while each of these terms illustrates the nuances of options within the process of distance learning itself.

Availability of cheaper PCs was followed by the availability of teaching materials that use computer performance - to make lessons which, in addition to text, also contain sound, picture or film record, with a possibility to make an interactive educational material as well as tests of knowledge and skills.

New opportunities for cheap making and editing of films or processing of sound and picture, which used to be available only to professional production companies, open up for schools, teachers and everyone who has a PC at their disposal. There are also opportunities for wide range of teachers to make multimedia educational materials, while the advent of the Internet made it possible to exchange these materials throughout the world.

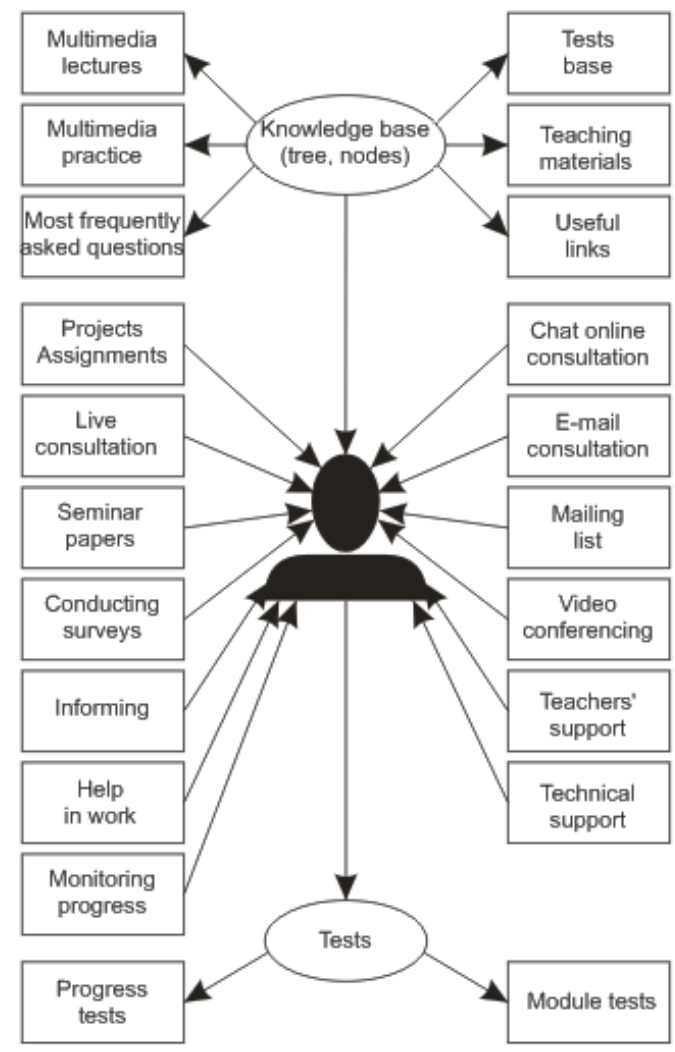

Figure 1: Some of the elements used in distance learning system

Numerous ideas together with the possibility of their quick exchange and distribution via the Internet have significantly improved the quality of educational material. New ideas regarding the 
individualization of the learning process also aroused interest. The first steps towards such form of education are being made in our region and faculties that provide it are established now.

E-learning represents instructional content or the way of learning by the use of electronic technology. The mainly used educational materials include materials on CD-ROMs, DVD-ROMs, WBT (WEB Based Training), CBT (Computer Based Training), AoD (Audio on demand), VoD (Video on demand), quizzes, synchronous and asynchronous conferencing.

The communication among users of this form of learning is electronic, while it could also occur in real time - it could be direct.

A computer serves as an intermediary in the communication between an electronic teacher - an application installed on some server and a user demanding an answer. When a teacher and student are physically far away from each other, then e-learning is used as d-learning and communication could be instantaneous or postponed.

\section{On Computer Graphics}

Computer graphics is not entirely original topic because it uses some of the established techniques such as geometry, algebra, optics and human psychology for defining and solving of problems.

Geometry is used for providing a framework for description of 2D and 3D space, while algebra techniques are used for defining and evaluation of equivalence concerning a particular space (Cvetković, 2006.).

The science of optics provides models for the description of light behaviour, while human psychology provides models for human vision and perception of colours.

The process of manufacturing is also in connection with computer description of designed objects, so the production is automated by means of the method named CAM (Computer-aided Manufacturing).

Technical experts, for example architects, regularly use the advantages of CAD applications in order to present sections of buildings or houses, as well as the positions of windows, doors, staircases and other elements. Thus, engineers are able to design electrical, plumbing, sewer and other types of installations based on the building section which appears in a particular ratio on the screen.

Computer graphics is nowadays used in many fields of work such as: industry, business, management in education, entertainment and so on. (Haern, Baker, 1996.).

\section{Interactive Computer Graphics}

Graphics provides one of the most natural ways of communication with a computer. An ancient Chinese proverb saying: "One picture is ten thousand words worth" has become a catchword in our society only after the advent of cheaper technologies for picture production, in the first place for print, and then for photographs (Foley, van Dam, Feiner, Hughes, 1996.).

Although static pictures are good for information exchange, dynamic ones prove to be even better. A variation on the Chinese proverb is that a motion picture is ten thousand static pictures worth. This especially applies to phenomena that are variable over a period of time but which could be real: 
- bending of airplane wings at supersonic flight

- development of human face from childhood to the old age

as well as abstract:

- growing trends, e.g. nuclear energy in the USA.

The use of dynamics is especially effective when a user is able to control the animation:

- by adjusting the speed

- of a part of the complete scene that is being presented

- of the number of the presented details

- of geometric ratios among objects in a scene.

The technology of interactive graphics mainly includes hardware and software for user's control of:

- dynamics of movement

- dynamics of updating.

Interactive graphics significantly increase our capabilities to:

- understand data

- be up-to-date with trends

- visualize real and imaginary objects

- create virtual worlds we can explore from an arbitrary point of view.

Making communication more efficient, graphics provides:

- more quality and more precise results and products

- more productivity and lower price of an analysis and designing.

\section{Electronic Teaching Material}

Educational materials are the most important element of distance education. Concerning classical education, they represent only a support to the teaching process which is teacher-centred. On the other hand, educational materials are the main source of new knowledge and skills in distance education. The materials are at the same time the controllers of the teaching process because they lead each learner through the process of training and direct them towards the desired aim. Their role is a complex one whereas their impact on the quality and result of distance education is substantial.

For the course in Computer Graphics within the accredited study programme of distance learning, teaching material consists of several parts:

1. the presentations for the theoretical part of the course that is divided into 15 teaching modules

2. the assessment of knowledge that enables students to check their knowledge after every teaching module

3. the material for application of program packages CorelDraw12 and Adobe Indesign CS, which consists of:
a. the explanations of particular options and program tools
b. the interactive tutorial presentation
c. the examples for students' work and practice. 


\section{Organization of the Course in Computer Graphics at Higher Education Technical School of Professional Studies at Novi Sad}

\section{Pre-exam Obligations and Points System}

Table 1 shows the scoring for computer graphics

Table 1: Scoring for computer graphics

\begin{tabular}{|c|c|c|c|c|c|}
\hline & & activity & maximum & minimum & $\begin{array}{l}\text { Mark - Total } \\
\text { No. of points: } \\
(56-100)\end{array}$ \\
\hline 1. & \multirow{2}{*}{ 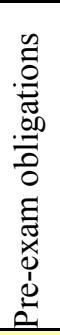 } & $\begin{array}{l}\text { CorelDraw } \\
12\end{array}$ & 25 & 14 & \multirow{3}{*}{$\begin{array}{ll}\text { Mark 6: } & 55-64 \\
\text { Mark 7: } & 65-74 \\
\text { Mark 8: } & 75-84 \\
\text { Mark 9: } & 85-94 \\
\text { Mark 10: } & 95-100\end{array}$} \\
\hline 2. & & $\begin{array}{l}\text { Adobe } \\
\text { Indesign CS }\end{array}$ & 25 & 14 & \\
\hline \multicolumn{2}{|l|}{3.} & $\begin{array}{l}\text { Test - } \\
\text { theoretical }\end{array}$ & 50 & 28 & \\
\hline
\end{tabular}

Students are obliged to attend lectures and practice work once a week. Lectures and practice work are available to students according to the provided timetable. New content is posted every week and it is available until the end of that semester. During one week, there are forums and practice exercises after the practice work (students have to complete the exercises before the set deadline - the end of the week). Teacher is online every Tuesday from 6 to 8 p.m. so that students could communicate with her/him through the chat room. (http://www.dl.vtsns.edu.rs/)

In addition to the practice exercises, all students have to take a test task on CorelDraw 12 and Adobe Indesign CS, which is marked. The time of this test is previously determined $\left(7^{\text {th }}\right.$ and $14^{\text {th }}$ week). If a student does not complete all test tasks (set from $1^{\text {st }}$ to $14^{\text {th }}$ week- it is clearly indicated in every exercise whether the task within practice should be completed and sent to a lecturer) with a required minimum of points, s/he can take that part again at the end of the course the $15^{\text {th }}$ week at School.

Students who fulfill the pre-exam obligations (all practice exercises and test tasks on CorelDraw and Adobe Indesign CS done with at least minimum of points) have the right to take the final exam at School according to the exam timetable. If a student does not achieve the minimum of points in one part, $\mathrm{s} / \mathrm{he}$ is allowed to take the same part at the end of the course. The final exam is organized at School according to the exam timetable.

\section{Syllabus for the course in Computer Graphics at Higher Education Technical School of Professional Studies at Novi Sad}

The course in Computer Graphics with the number of teaching instruction classes based on $1+3$ scheme is one of the compulsory general courses and it is included in the curriculum for study 
programmes of information technologies and all study programmes within the department of Graphics (graphic design, graphic engineering, applied photography and web design). The theoretical part of the course is the same for all students as is the material for practice work in which differences exist only in the examples intended for student' independent work. These examples are modified to suit to each of the study programmes. (Gemovic, Subic, 2007.)

\section{Course content}

Theoretical part of the course is divided into 14 parts and comprises the following content:

Basic components of graphic processing; Application of Computer Graphics: Classification of graphic applications, Conceptual framework of interactive graphics.

Graphic systems: What is provided by the connection between a computer and graphic application?

Diagrams and graphs; Designing by computer, Virtual reality; Data visualization; The Use of graphic system.

Hierarchy of graphic software: Simple graphic libraries; Visualization tools; Modeling tools; Rendering tools; Animation tools; Simulation tools; Virtual reality tools; Web3d tools; Format converting tools.

Geometric transformations: 2D computer graphics; Orthogonal Projections

Vector and raster graphics: Vector graphics; Raster graphics; Formats of graphic files; Raster images

Graphic communication; The theory of colours

Graphic hardware: Input devices; Pointing input devices; Scanners; Other input devices, Display technologies

Modelling ways: Wire-frame model, Edge representation, Volume representation, Procedural models

Computer animation: Lighting modes - light sources, Reflectivity modes, Shading techniques, Hidden surface techniques

Graphic formats: Configuration of image file, Image compression, Colour reduction methods, Most frequently used graphic formats

The syllabus for practice work is divided into 2 parts and is made up of two courses lasting 7 weeks during which the students learn how to use the programs of CorelDraw12 and Adobe Indesign CS.(Aleksić, 2005; Desimirović 2006.; Schwartz, Phillis 2003.)

\section{The Efficiency of Application of Electronic Learning to the Course in Computer Graphics}

The research included 59 students of the study programme Information Technologies $\left(1^{\text {st }}\right.$ year of studying, $2^{\text {nd }}$ semester) at Higher Education Technical School of Professional Studies at Novi Sad. The aim of the research was the efficiency of a contemporary course in Computer Graphics while the subject of research was theoretical and empirical study of students' achievements made by application of innovative models of teaching computer graphics.

For the research purposes, course content in Computer Graphics for the study programme of Information Technologies was used as the programme. The course content was based on innovative 
models of teaching which are modified for the purposes of distance learning. The course within the conducted research was organized on a weekly basis and lasted 15 weeks. Students' activities and obligations were defined in advance, as is provided in the previous section of this paper.

The students and teachers had a rapid and easy access to the system contents, which increased the efficiency and quality of the education process. The teachers were provided with the possibility to successfully undertake the activities needed for the realization of distance education: preparation of course contents using the Internet, course design, design and posting of teaching materials, monitoring of work and consultation with students, assessment of students.

The aim of the research was to determine the effects of programme application through innovative models of work in the course of Computer Graphics.

\section{The Innovative Model of Work on the Course in Computer Graphics}

Within the innovative model of work on the course in Computer Graphics, interactive tutorials for every course unit were organized. A tutorial comprises multimedia material which gradually, step by step, presents to a student the way in which graphic objects are created, and thus it teaches a student how to use the tools and functions provided by the program environment of CorelDraw 12 and Adobe Indesign CS.( http://www.cs.sfu.ca/CourseCentral/365/li/material/syllabus.html )

Wink program was used for the making of these tutorials. Wink is a free software tool for creating presentations and tutorials about the use of some software package. (http://www.debugmode.com/wink/)

Tutorial presentations created in Wink program look like a lecture presented by a teacher at a class or practice work within program environment. (http://www.debugmode.com/wink/)

The advantages of such presenting of a teaching material for students who applied for distance learning are huge:

- easy understanding of the CorelDraw12 and AdobeInDdesignCS program possibilities and work in the given environment

- visual display of creating graphic objects

- the possibility of stopping the presentation and independent creation of the presented

- the possibility of revising a particular teaching material

- step-by-step approach to presenting.

Following this type of presentations, a distance-learning student gets a visual picture of the creation of graphic objects and of their layout and organization in the environment. For the purposes of a better and more detailed explanation of the concepts and use of tools, the author of a tutorial is given the possibility of inserting comments and explanations in specific parts of the interactive material, as it is presented in Figure 2.

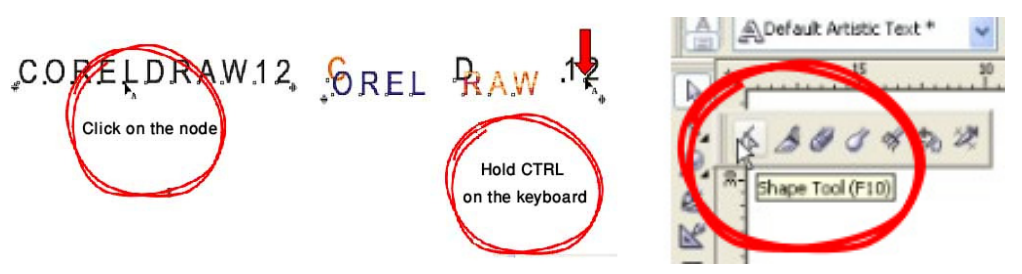

Figure 2: Comments in Wink program 
The author is also allowed to insert control buttons to direct the teaching material flow and stop it after one whole part of the presentation completes, as Figure 3 shows.

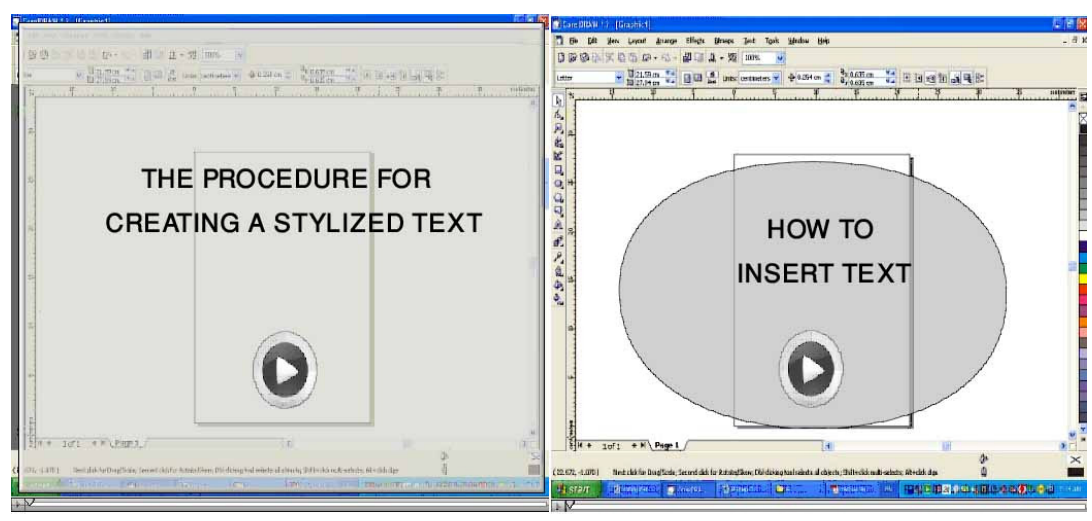

Figure 3: Control buttons in Wink program

The basic format of the presentation is Flash that is presented in a web-browser using a free Macromedia Flash Player which is already installed in every computer or it could be easily installed when the presentation is run for the first time.

Group I students were given materials in printed form without the interactive content. Group II students were given the same printed material but they were given an explanation and an interactive way to create a similar problem.

\section{The Conducted Research}

The aim of the research was to determine the effects of the application of the programme through innovative models of work on the course in Computer Graphics.

Research techniques and methods used for this research are:

- $\quad$ survey - getting students' opinions on advantages and disadvantages of such organization of a course;

- testing - determining students' previous knowledge of the course in Computer Graphics, i.e. the initial testing of knowledge

Research instruments:

- questionnaires and

- knowledge tests.

A survey of students - a survey conducted after the research included the students of experimental classes and it set out to provide the students' impressions of the experimental programme realization, i.e., of the innovative ways of work and learning. The survey was anonymous so as to let students be more open when expressing their opinions. The questions asked in the survey are provided in the tables presenting the results.

Measuring of the relevant parameters and the analysis of the results were done according to the standard statistical methods. 


\section{Research Results}

The tables of research results present two categories of the crucial points. The first category is Impressions about teaching material, which is presented by the elements of marks given to the quality of teaching material, organization of teaching material and technical quality of teaching material (See Table 2 and Figure 4). The second category is Application of teaching material, which is presented by the elements of marks given to clarity of the presented teaching content and to the possibility for independent dealing with tasks after the presentation of teaching material (See Table 3 and Figure 5).

Table 2: Impressions about teaching material

\begin{tabular}{|l|l|l|l|l|l|l|}
\hline \multirow{2}{*}{ the element of mark } & \multicolumn{2}{|c|}{ excellent } & \multicolumn{2}{c|}{ very good } & \multicolumn{2}{c|}{ good } \\
\cline { 2 - 7 } & I group & II group & I group & II group & I group & II group \\
\hline $\begin{array}{l}\text { The quality of teaching } \\
\text { material }\end{array}$ & 8 & 16 & 12 & 10 & 8 & 2 \\
\hline $\begin{array}{l}\text { The organization of } \\
\text { teaching material }\end{array}$ & 4 & 16 & 14 & 8 & 10 & 4 \\
\hline $\begin{array}{l}\text { The technical quality of } \\
\text { teaching material }\end{array}$ & 4 & 14 & 16 & 9 & 8 & 5 \\
\hline
\end{tabular}

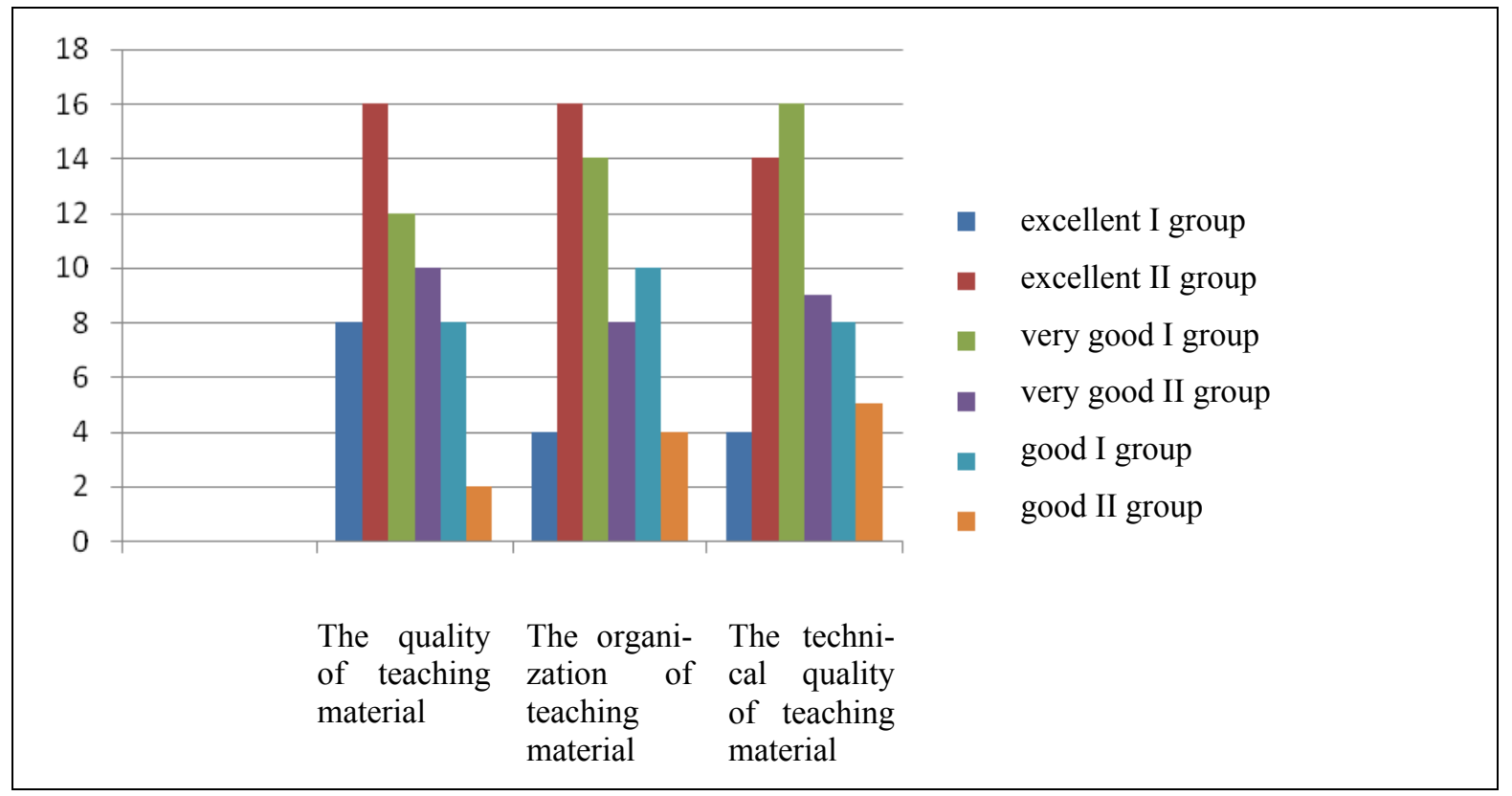

Figure 4: Diagram of the Table 2 
Table 3: Application of teaching material

\begin{tabular}{|l|c|c|c|c|c|c|}
\hline \multirow{2}{*}{ the element of mark } & \multicolumn{2}{|c|}{ excellent } & \multicolumn{2}{c|}{ very good } & \multicolumn{2}{c|}{ good } \\
\cline { 2 - 7 } & I group & II group & I group & II group & I group & II group \\
\hline $\begin{array}{l}\text { The clarity of the presented } \\
\text { teaching content }\end{array}$ & 6 & 12 & 12 & 10 & 10 & 6 \\
\hline $\begin{array}{l}\text { The possibility for inde- } \\
\text { pendent dealing with tasks } \\
\text { after the presentation of } \\
\text { teaching material }\end{array}$ & 8 & 12 & 10 & 12 & 10 & 4 \\
\hline $\begin{array}{l}\text { Coping within the presented } \\
\text { program }\end{array}$ & 4 & 14 & 4 & 9 & 10 & 5 \\
\hline
\end{tabular}

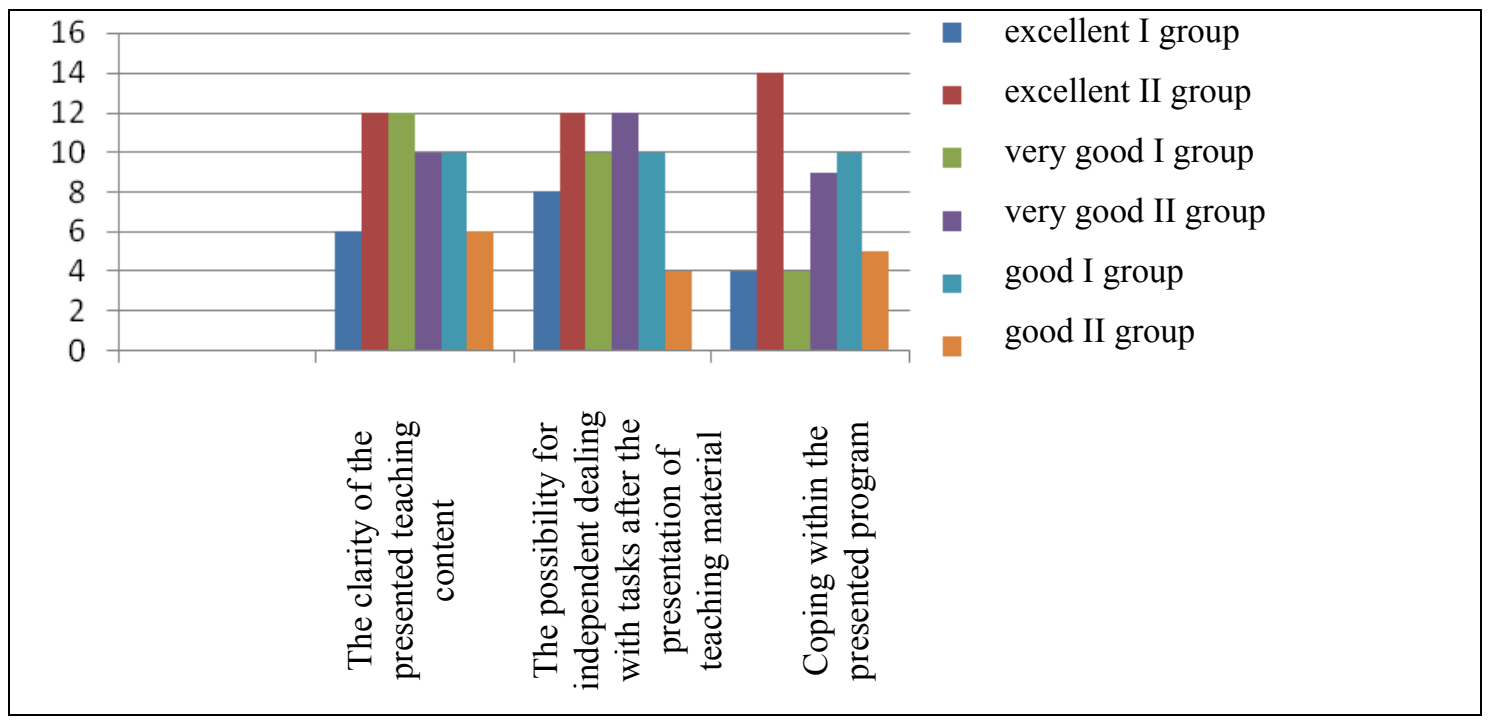

Figure 5: Diagram of Table 3

Comparing the obtained values, it is concluded that the II group is more satisfied with the technical quality and organization of teaching material. This implies that it was easier for them to follow the teaching material and deal with working in the presented program environment, as well as to apply the learnt matter. This conclusion is based on the Figure 5.

The results after processing are presented in Tables 4 and 5 and Figures 6 and. It is realized and concluded that II group did the task more successfully, although a smaller percentage of students from group II had previous knowledge in this field. This fact directly implies good understanding of the matter by means of interactive presentation and subsequent easy recognition and application of the gained knowledge. 
Table 4: Results after processing

\begin{tabular}{|c|c|c|c|}
\hline \multirow{2}{*}{$\begin{array}{l}\text { Previous knowledge of work in } \\
\text { the program of CorelDraw }\end{array}$} & \multicolumn{3}{|l|}{ Marks } \\
\hline & excellent & satisfactory & $\begin{array}{l}\text { without previ- } \\
\text { ous knowledge }\end{array}$ \\
\hline I group & 3 & 10 & 15 \\
\hline II group & 2 & 11 & 16 \\
\hline
\end{tabular}

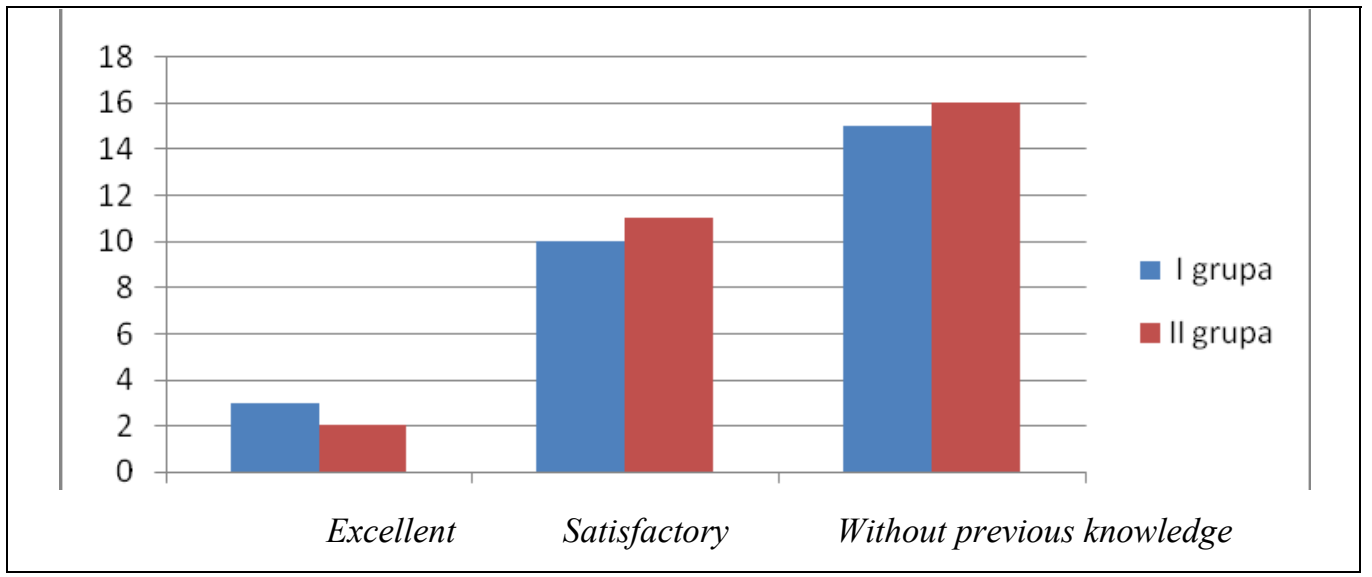

Figure 6: Previous knowledge of work in the program of CorelDraw12

Table 5: Results after processing

\begin{tabular}{|c|c|c|c|}
\hline \multirow{2}{*}{ Success in performing tasks } & \multicolumn{3}{|l|}{ Marks } \\
\hline & excellent & satisfactory & unsatisfactory \\
\hline I group & 10 & 11 & 7 \\
\hline II group & 14 & 10 & 5 \\
\hline
\end{tabular}

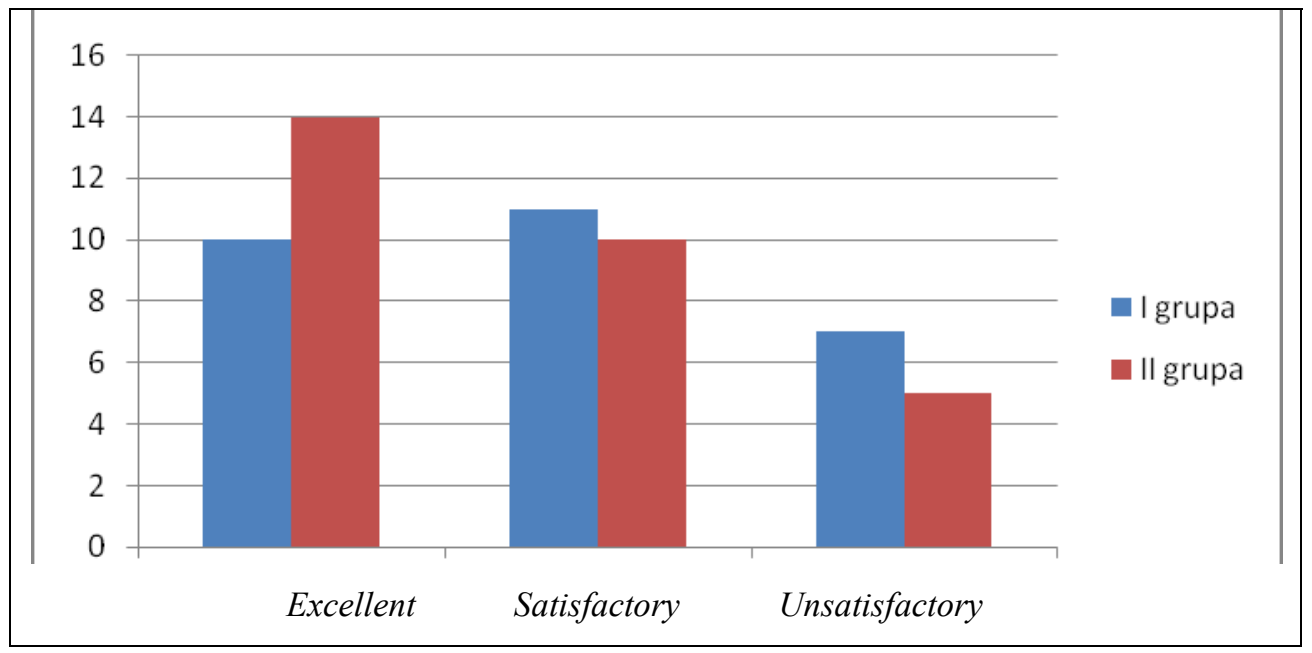

Figure 7: Success in performing tasks 


\section{Conclusion}

The advantages of interactive presentation of teaching material in the distance learning system are enormous. The advantages of eLearning platform for the course in Computer Graphics are the following:

1. achieving considerable market competitiveness in the region;

2. obtaining the system that meets the requirements set in the Standards for accreditation of higher education institutions;

3. obtaining an insight into the individual progress of every student;

4. getting control and supervision of the work of every teacher;

5. technical support is available to students 24 hours a day.

Of course this way of mastering the material also has disadvantages:

1. the lack of personal contact in relation to teacher-student and student-student

2. require a high level of activity and discipline students

3. problems related to technology

There is the unlimited number of repetition depending on the student's individual needs. Easy understanding of the matter, visual presentations of creating concrete examples with usage and customization of the tools certainly contribute to easier understanding of the matter and practical application of the gained knowledge.

This kind of work, with interactive presentations, is an attempt to reduce or mitigate the disadvantages. Any number of repetitions, depending on the individual student's needs, reduces the lack of personal contact in distance learning. Easily mastering, visual development with specific examples how to use tools and settings certainly leads to facilitate the learning materials and application of knowledge in practice. Interactive presentation does not require additional technical support for the view and thus makes the problems related to technology, smaller.

The interactive presentation is recommended for use in regular classes because of these advantages of repetition, which is the number of repetitions depends on the individual. It is recommended to use this type of presentation materials wherever the material that is presented graphic type, and users are expecting some activity in the programming environment.

\section{References}

Dragan, C. (2006). Računarska grafika, CET, Beograd.

Foley, J., van Dam, A., Feiner, S., \& Hughes, J. (1996). Computer graphics - Principles and practice (2nd ed.). Addison-Wesley Publishing Company.

Gemovic, B., \& Subic, N. (2007). Kompjuterska grafika, VTSNS, Novi Sad.

Haern, D., \& Baker, P. (1996). Computer graphics - C version (2nd ed.). Prentice-Hall.

Nenad, D. (2006). InDesign za početnike, PC knjiga, Beograd 2006.

Rizvic S., \& Kunovac E. (1998). Računarska grafika, Ministarstvo za obrazovanje, nauku, kulturu i sport Federacije BiH, Sarajevo.- elektronska knjiga

Schwartz, S., \& Davis, P. (2003). CorelDraw1 1 for Windows, CET. Beograd.

Zvonko, A. (2005). CorelDraw 12, Kompjuter biblioteka, Beograd.

Zvonko, A. (2005). InDesignCS2, Kompjuter biblioteka, Beograd. 


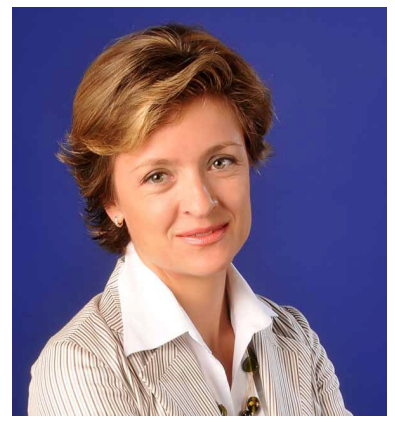

\section{Biographies}

MSc Biljana Gemović is a lecturer at the vocational program of mechanical and engineering graphics and has twelve Profit for experience in teaching vocational subjects in the field of Technical Engineering (Computer graphics, CAD);

- Competence in the area of the thesis as well as participation in professional symposia on topics in the field of improving the quality of management and computer engineering, as well as participation in the innovation program for engineering education in the field of computer graphics and CAD at the Technical University of Applied Studies in Novi Sad ;

- years of experience in teaching vocational subjects in the field of graphic engineering and mechanical engineering (AutoCad, Computerized design) software packages work in CorelDraw and AutoCad

- extensive experience in the application of CAD technology, implementation of quality system ISO 9001, ISO 18001 and HACCP

- participation in the drafting of technical and technological documentation

- External auditors for the OHSAS 18001 standard and an internal auditor for ISO 9001

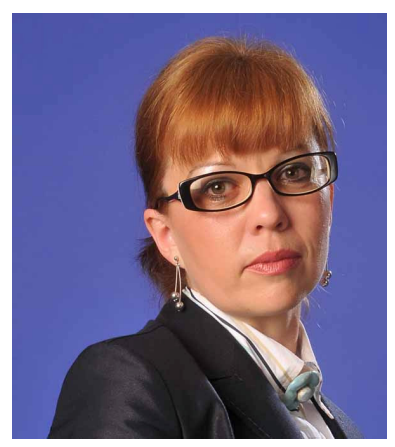

Nataša Subić, Master of Computer Engineering

- Extensive experience in teaching and working in the field of computer engineering base (MSOffice suite of software) and engineering graphics (CorelDRAW, Adobe Photoshop, Adobe Indesign).

- More years of experience as an expert on matters introduction to programming, web languages and tools.

- Participating in preparing technical documentation for a Tempus project, participation in professional Symposiums topics related to innovation and education program of information and communication technologies. 